Original Research Article

\title{
Efficacy, safety and cost effectiveness of levocetrizine and ebastine in allergic rhinitis: a comparative study
}

\author{
Sharadashri Rao ${ }^{1}$, Sunil Pai ${ }^{2 *}$, Kuladeepa Ananda Vaidya ${ }^{3}$, Tara V. Shanbhag ${ }^{1}$
}

\begin{abstract}
${ }^{1}$ Department of Pharmacology, ${ }^{2}$ Department of ENT,

${ }^{3}$ Department of Pathology, Srinivas Institute of Medical Sciences and Research Centre, Mukka, Mangalore, India
\end{abstract}

Received: 25 June 2018 Accepted: 26 July 2018

\section{*Correspondence to:}

Dr. Sunil Pai,

Email: docsunilpai@gmail.com

Copyright: (C) the author(s), publisher and licensee Medip Academy. This is an openaccess article distributed under the terms of the Creative Commons Attribution NonCommercial License, which permits unrestricted noncommercial use, distribution, and reproduction in any medium, provided the original work is properly cited.

\begin{abstract}
Background: Allergic rhinitis is a ubiquitous aliment affecting a large population of individuals. The mainstay of treatment includes antihistamines and topical steroids. With a large assortment available, the choice of the drugs needs to be non-random and evidenced based. Hence this study was undertaken to compare Levocetrezine and Ebastine in terms of efficacy, safety and cost effectiveness in treatment of allergic rhinitis.

Methods: Newly diagnosed patients with allergic rhinitis were categorized into two groups and treated with Levocetrizine $5 \mathrm{mg}$ and Ebastine $20 \mathrm{mg}$ per day respectively. Severity of the symptoms at the commencement and at the end of second and the fourth weeks of therapy were assessed using a four-point Likert scale and assigning a Total Nasal Symptoms Score (TNSS). The primary efficacy measure was mean change from baseline TNSS at each follow up visit. Change in TNSS was compared using Independent sample test. Adverse effects in both the groups were compared using Chi square test. Cost effectiveness was inferred by calculation of the Average Cost Effectiveness Ratio.

Results: A total of 159 patients 84 from Levocetrizine group (L group) and 75 from the Ebastine group (E group) were available for study. At the end of second week, the E group showed a better reduction in TNSS(p-0.04). However, both the groups showed similar reduction in TNSS at the concluding visit (p-value of 0.09). The incidence of adverse effects was significantly higher in the L than in E. Levocetrezine was found to be more cost effective than Ebastine.

Conclusions: Levocterezine and Ebastine are equally efficacious in treatment of allergic rhinitis. Hence treatment will have to be personalized to the individual patients based on other factors such as adverse drug effects and cost effectiveness.
\end{abstract}

Keywords: Allergic rhinitis, Cost-effectiveness Ebastine, Efficacy, Levocetrezine

\section{INTRODUCTION}

Allergic rhinitis is one of the common conditions affecting a large percentage of population. The prevalence of the disease ranges from $9 \%$ to as high as $42 \%$. It is characterised by acute nasal and eye symptoms following exposure to environmental allergens. The symptoms of sneezing, rhinorrhea with nasal congestion can be seasonal or perennial affecting the quality of life, including sleep, social interaction, and work. ${ }^{1-4}$
Antihistamines essentially remain the fundamental group of drugs in treatment of allergic rhinitis. They not only reduce the disease symptomatology but also improve quality of life..$^{5,6}$

Levocetirizine is the active R(-) enantiomer of cetirizine. Ebastine another second generation H1-antagonists gets rapidly converted to its active metabolite carbastine and has a long plasma half-life (10-16 hours). It is reported to be nonsedating and is effective in skin and nasal allergies. ${ }^{7}$ 
Due to loss of productivity allergic rhinitis incurs higher indirect cost. Hence pharmacotherapy of allergic rhinitis should in addition to other factors also take into account the cost and economic value of available drugs. ${ }^{8}$

A survey of literature reveals few published studies comparing levocetirizine and ebastine. Hence this study was undertaken to explore the lacuna in the data focusing on the Indian population presenting at a tertiary care hospital.

\section{METHODS}

This study was conducted in department of otorhinolaryngology at Srinivas Institute of Medical College and Research Centre which is situated in the southern parts of coastal Karnataka. The study was initiated after obtaining written approval from the Institutional Ethics Committee (IEC). Written informed consent was obtained from the patients of the study group.

\section{Inclusion criteria}

- Diagnosed cases of allergic rhinitis of either sex between the age group of 18-60 yrs.

\section{Exclusion criteria}

- Pregnant or lactating women

- Those with nasal polyposis or infectious pathology during physical examination

- Patients who underwent major surgery within 4 weeks

- Patients who have had upper respiratory tract infection within 3 weeks prior to study

- Patients with a history of hypersensitivity to ebastine or levocetirizine

- Patients with history of bronchial asthma.

The study was carried out over a period of six months from December 2016 to June 2017. A detailed clinical history including demographic data and symptoms were recorded. Patients were evaluated for the nasal symptoms of rhinorrhea, nasal itching, nasal obstruction, and sneezing using a 4-point Likert scale and the severity was graded from 0 to $3(0=$ no symptom, $1=$ mild, $2=$ moderate, $3=$ severe). The Total Nasal Symptom Score (TNSS) was obtained by adding up the individual scores for each of the four symptoms, with a total possible score ranging from 0 (no symptoms) to 12 (maximum symptom intensity). The patients were then enrolled by convenient sampling and categorised in two groups. One group received $5 \mathrm{mg}$ of Levocetrizine (L group) once a day and the other received $20 \mathrm{mg}$ of Ebastine (E group) once a day.

Follow up was done at the end of the second and fourth weeks (total 2 visits). Changes in TNSS scoring and side effects if any were noted at each visit. The primary efficacy measure was mean change from baseline TNSS at each follow up visit.
For pharmacoeconomic comparison between the two groups only direct cost (including physician services) was considered in the study. Efficacy of treatment was defined as "percentage reduction in TNSS compared with baseline."

The subjects were informed to contact the principal investigator if they experience any untoward effects in between the time of visits.

\section{Statistical analysis}

Statistical analysis was done using Statistical package for social service (SPSS) software version 18. Baseline parameters like age and TNSS of the two groups were compared using Independent sample test. Present study showed nearly $20 \%$ attrition rate. Hence for the purpose of calculation of the mean baseline TNSS the scores of only those patients retained in the study until its conclusion were considered.

Effect of drugs in terms of change in TNSS was compared using Independent sample test. Adverse effects in both the groups were compared using Chi square test. $p<0.05$ was considered statistically significant. Adverse CostEffectiveness ratio was calculated by dividing the total cost of the drugs by the effectiveness.

\section{RESULTS}

Of the 200 patients enrolled initially a total of 159 patients were available for analysis at the end of the study period84 from Levocetrizine group and 75 from the Ebastine group. A total of 20 patients (6 in L group, 14 in E group) did not report for the first follow-up visit and a total of 14 patients ( 5 in L group and 9 in E group) were unavailable for assessment at the end of four weeks. The remaining 7 patients ( 5 in $\mathrm{L}$ and 2 in $\mathrm{E}$ group) were changed over to topical steroids after the first visit.

The demographic details and the mean baseline TNSS for each group are presented in Table 1.

\section{Table 1: Comparison of demographics and baseline} parameters in $\mathrm{L}$ and $\mathbf{E}$ groups.

\begin{tabular}{|lll|}
\hline Characteristics & $\begin{array}{l}\text { Levocetirizine } \\
(\mathbf{n = 8 4})\end{array}$ & $\begin{array}{l}\text { Ebastine } \\
(\mathbf{n = 7 5 )}\end{array}$ \\
\hline $\begin{array}{l}\text { Number of patients } \\
\text { included in the study }\end{array}$ & 100 & 100 \\
\hline $\begin{array}{l}\text { Number of patients } \\
\text { completed the study }\end{array}$ & 84 & 75 \\
\hline Male & $46(54.8 \%)$ & $34(45.3 \%)$ \\
\hline Female & $38(45.2 \%)$ & $41(54.7 \%)$ \\
\hline Mean age & $31.52 \pm 11.07$ & $29.21 \pm 9.2$ \\
\hline
\end{tabular}

The mean age of the patients in $\mathrm{L}$ and $\mathrm{E}$ groups was $31.52 \pm 11.07$ and $29.21 \pm 9.2$ respectively. 
Table 2: Mean TNSS in each group recorded at baseline and at each follow up visit.

\begin{tabular}{|lllc|}
\hline Visit & \multicolumn{2}{l}{$\begin{array}{l}\text { Mean TNSS } \pm \text { SD in two } \\
\text { groups }\end{array}$} & $\begin{array}{c}\text { p- } \\
\text { value }\end{array}$ \\
\hline Levocetirizine & Ebastine & \\
\hline Baseline & $9.08 \pm 1.23$ & $9.44 \pm 1.22$ & 0.07 \\
\hline $2^{\text {nd }}$ week & $5.20 \pm 1.4$ & $4.80 \pm 0.92$ & 0.04 \\
\hline $4^{\text {th }}$ week & $2.51 \pm 1.42$ & $2.13 \pm 1.4$ & 0.09 \\
\hline
\end{tabular}

Both the groups were comparable; $\mathrm{p}$ value $>0.05$. In the levocetirizine group, mean baseline TNSS was 9.08 \pm 1.23 . In the ebastine group mean baseline TNSS was 9.44 \pm 1.22 . There was no significant difference between the two groups. $\mathrm{p}$ value $>0.05$ (Table 2 ).
Patients in both the groups showed reduction in TNSS from 0 weeks towards the end of second and fourth week. At the end of second week, the E group showed a better reduction in TNSS which was statistically significant with a p-value $0.04(<0.05)$. But towards the end of fourth week, both the groups showed similar reduction in TNSS with p-value of 0.09 (Table 2).

Side effects reported by both the groups included dryness of mouth, sedation, headache and fatigue. In addition, 15 patients in levocetirizine group complained of constipation. The number of patients reporting these symptoms in each of the groups is presented in Table 3.

Table 3: Average Cost Effectiveness of L vs E.

\begin{tabular}{|lllll|l|}
\hline Group & $\begin{array}{l}\text { Cost/patient (P) } \\
\text { (in Rs.) }\end{array}$ & $\begin{array}{l}\text { Total number } \\
\text { of patients }(\mathbf{n})\end{array}$ & $\begin{array}{l}\text { Total cost } \\
(\mathbf{P} \text { x n })\end{array}$ & $\begin{array}{l}\text { Effectiveness } \\
\text { (\% reduction in TNSS) }\end{array}$ & ACEF $^{\text {( }}$ \\
\hline Levocetirizine & 356 & 84 & 29904 & 73.4 & 407.4 \\
\hline Ebastine & 440 & 75 & 33000 & 77 & 429 \\
\hline
\end{tabular}

${ }^{a}$ Average Cost Effectiveness Ratio

A total of 72 out of 84 patients in the L group developed adverse effects as opposed to 28 out of 75 patients in $E$ group. The difference in the incidence of side effects in between patients of the two groups was statistically significant ( $\mathrm{p}$ value $<0.05$ ). Average cost effectiveness ratio of levocetirizine and ebastine are declared in Table 3.

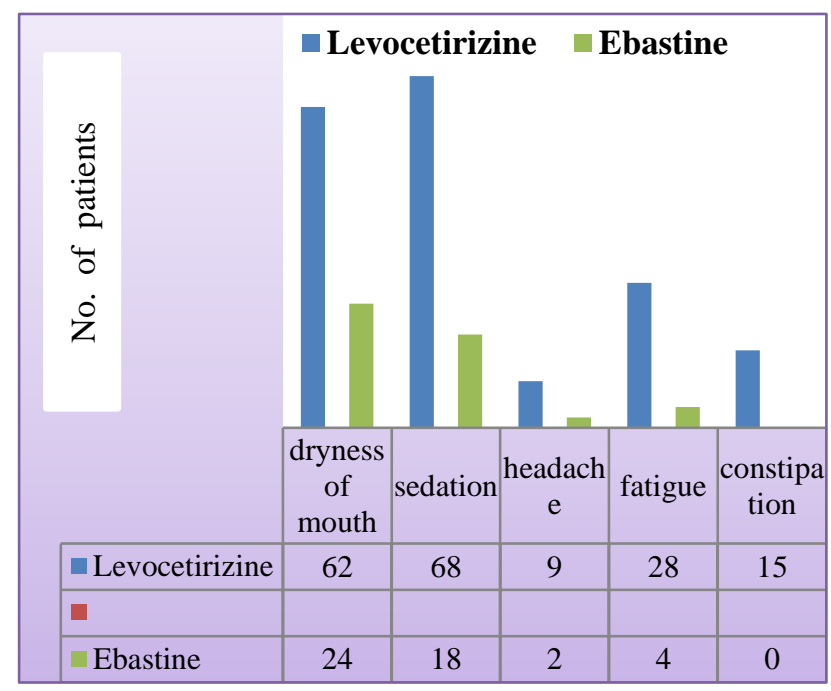

Figure 1: Proportion of patients with adverse effects in patients on levocetirizine and ebastine.

\section{DISCUSSION}

Antihistamines and intranasal corticosteroids are the mainstay of treatment of allergic rhinitis. Since first generation antihistamines share anti-cholinergic effects, second generation antihistamines such as levocetirizine, cetirizine, loratadine, desloratadine, fexofenadine and ebastine are preferred..$^{9,10}$

Out of 200 patients initially enrolled in the present study we experienced attrition rate of about $20 \%$ being slightly higher in the E group (25\%) as against the L group (16\%). At the end of the study period however there was no significant difference in average age or the baseline TNSS between the two groups making them fairly comparable.

Authors can speculate here if the higher attrition rate in $\mathrm{E}$ group (n-14) might have been due to rapid improvement in the symptoms occurring within the first two weeks as compared to those in $\mathrm{L}(\mathrm{n}-6)$ group since there was a significant difference in the TNSS at the end of two weeks with patients in $\mathrm{E}$ group faring far better than those in $\mathrm{L}$ group. Also supporting this is the fact that the number of patients that dropped out of the study during the latter half are less (E-9 and L-5) than in the former probably due to a lesser decrease in the symptoms.

The difference in the mean TNSS between Ebastine and Citrezine at the end of the fourth week was not significant making both of them almost equally efficacious in the long run. This is similar to the experiences of Goyal et. al whose study on treatment of urticaria showed similar efficacy between levocetirizine $5 \mathrm{mg}$ and Ebastine 20mg. ${ }^{11}$

Dryness of mouth, sedation, headache, fatigue and constipation were the adverse effects seen in these patients. Though these adverse effects were significantly more common in patients on levocetirizine it did not result in a 
higher dropout rates compared to Ebastine. The adverse effects reported did not require stoppage of treatment, reduction of dose, nor did they require any treatment. These findings were similar to study done by Goyal et al. ${ }^{11}$

The lower ACER of levocetirizine (407.4) as compared to Ebastine (429) in the present study illustrates the fact that levocetirizine is more cost effective than ebastine. This is similar the study done by Goodman et al showed levocetirizine to be more cost effective than other secondgeneration antihistamines. Since treatment of allergic rhinitis is generally long term and adherence to treatment is important this attribute in addition to the efficacy plays a very significant role at the time of therapeutic decision making. ${ }^{4,12}$

Attrition rate of nearly $20 \%$ in an already small sample of patients which would have to some extent influenced the ACER is a major limitation of this study. Also, authors were unable to do crossover study in the present patients

\section{CONCLUSION}

The two antihistamines Levocetrizine and Ebastine were comparable in terms of efficacy in treatment of allergic rhinitis. With this being the case the physician may have to consider other factors such as adverse drug effects and the cost effectiveness of the drugs and customize the therapy according to the individual patients' profiles.

Funding: No funding sources Conflict of interest: None declared

Ethical approval: The study was approved by the Institutional Ethics Committee

\section{REFERENCES}

1. Stubner P, Zieglmayer, Horak F. A direct comparison of the efficacy of antihistamines in sar and par: randomised,placebo- controlled studies with levocetirizine and loratadine using an environmental exposure unit- The Vienna Challenge Chamber (VCC). Curr Med Res Opin. 2004;20(6):1-6

2. Downie SR, Andersson M, Rimmer J, Leuppi JD, Xuan W, Akerlund A, Peat JK, Salome CM. Symptoms of persistent allergic rhinitis during a full calendar year in house dust mite-sensitive subjects. Allergy. 2004 Apr;59(4):406-14.

3. Greiner AN, Meltzer EO. Overview of the treatment of allergic rhinitis and nonallergic rhinopathy. Proceedings of the Am Thoracic Soc. 2011 Mar 1;8(1):121-31.

4. Goodman MJ, Jhaveri M, Saverno K, Meyer K, Nightengale B. Cost-effectiveness of secondgeneration antihistamines and montelukast in relieving allergic rhinitis nasal symptoms. American Health Drug Benefits. 2008;1(8):26-33.

5. Mösges R, König V, Köberlein J. The effectiveness of levocetirizine in comparison with loratadine in treatment of allergic rhinitis:a meta-analysis. Allergology International. 2011 Jan 1;60(4):541-6.

6. Katzung BG, Masters SB, Trevor AJ. Basic and Clinical Pharmacology. 11 ${ }^{\text {th }}$ Ed. New Delhi: Tata McGraw Hill Education Private Limited;2009;278.

7. Tripathi KD. Essentials of Medical Pharmacology. $7^{\text {th }}$ ed. New Delhi: Jaypee Brothers Medical Publishers (P)Ltd;2014;166-7.

8. Simoens S, Laekeman G. Pharmacotherapy of allergic rhinitis: a pharmaco-economic approach. Allergy. 2009;64(1):85-95.

9. Small P, Kim H. Allergic rhinitis. Allergy Asthma Clin Immunol. 2011;7(1):1-8.

10. Skidgel RA, Kaplan AP, Erdos EG. Histamine, Bradykinin and Their antagonist: Goodman and Gilman's The pharmacological Basis of Therapeutics. $12^{\text {th }}$ ed. New York: McGraw-Hill;2011;925.

11. Goyal V, Gupta A, Gupta O, Lal D, Gill M. Comparative Efficacy and Safety of Ebastine $20 \mathrm{mg}$, Ebastine $10 \mathrm{mg}$ and Levocetirizine $5 \mathrm{mg}$ in Acute Urticaria. J Clin Diagnos Res: JCDR. 2017 Mar;11(3):WC06.

12. Ciprandi G. Clinical utility and patient adherence with ebastine for allergic rhinitis. Patient Prefer Adherence. 2010;4:389-95.

Cite this article as: Rao S, Pai S, Vaidya KA, Shanbhag TV. Efficacy, safety and cost effectiveness of levocetrizine and ebastine in allergic rhinitis: a comparative study. Int J Basic Clin Pharmacol 2018;7:1748-51. 